\section{Handbook of Chemical Microscopy}

By Prof. Émile Monnin Chamot and Prof. Clyde Walter Mason. Vol. 2: Chemical Methods and Inorganic Qualitative Analysis. Second edition. Pp. xi +438 . (New York: John Wiley and Sons, Inc.; London: Chapman and Hall, Ltd., 1940.) $30 s$. net.

$\mathrm{T}$

HE rapid development in recent years of microchemical methods of analysis has called forth an excellent series of text-books on various aspects of the subject and, of these, Chamot and Mason's "Handbook of Chemical Microscopy" holds a deservedly high place. In the second edition of vol. 2 now under review, most of the subject-matter in the original work (reviewed in NATURE, 130, 619; 1932) has been retained but a number of new tests have been included, some of them employing organic reagents such as dipicrylamine, nitrobarbituric acid and diphenylearbazide. The most extensive additions have been to the sections dealing with the detection of the alkali metals, the metals of Group IV of the periodic elassification and the anions of the sulphur group where tests have now been included for the polythionates; a scheme for the identification of the various sulphur-containing anions has also been drawn up. To illustrate these new procedures there have been included forty-eight additional photomicrographs. All the photographs are excellently clear and the same care has been expended in making the descriptive matter lucid and yet concise. The text is remarkably free from errors, while there is a good index. The volume is handsomely bound, so that the authors and publishers have collaborated to produce a book which is indeed a joy to handle and to use.

Beyond the "Isms"

By Olaf Stapledon. (Searchlight Books, No. 16.) Pp. 128. (London: Martin Secker and Warburg, Ltd., 1942.) 28 . net.

$\mathrm{T}$ HERE has been a remarkable spate of books inspired by the War, and they are none of them of the furious anti-Hitler type which the case would warrant. The writers are stirred by social passion among themselves. Let them use the war as binding the nation in determined and religious ardour which will stretch far beyond the war itself. Sir Richard Gregory's "Religion, Science and Civilization" is, of course, of ampler scope and full of interesting matter. It leans in the same direction as Mr. Stapledon in stressing the religious side but avoiding any orthodox religions. The most striking feature of all these religious-social war exhortations is that they come from and go to the religious who frankly discard the accepted creed of the Church of England or any other church. Their attitude is forward-looking, but not attached to any church. The future of organized religion will therefore become more and more vague and insincere, unless the discard of impossible doctrines and legends is frankly made.

This is being done in certain churches, and, of course, in multitudes of private prayers.

The crisis is a useful one. A new archbishop to set the tone.

Religion is our attitude towards the Infinite in company with and for the good of others. This must differ from worshipper to worshipper. The Infinite may find its own.
Supplement to the British Pharmaceutical Codex, 1934

Part 1: Monographs (New Monographs). Pp. iv + 101. (London: The Pharmaceutical Press, 1942.) 5s. $6 d$.

$\mathrm{T}$

HE British Pharmaceutical Codex was last published in 1934, but it has been brought up to date by the issue of three supplements in the last few months. The first supplement deals with dressings, while the second contains additions and amendments to the formulæ for galenical and other preparations in Part 3 of the Codex. It is designed to overcome difficulties arising from the War by authorizing the use of alternative formulæ for preparations in which certain of the ingredients are either in short supply or reserved for more important purposes. The third supplement, which corresponds with Part 1 of the Codex, is most likely to interest the scientific man. It contains 66 new monographs describing substances recently introduced in medicine, and substances liberated by the recent emergency legislation from the restrictions imposed by foreign patents. About half of these substances have already been described in the various addenda to the British Pharmacopœia; the remainder now receive their first official description in Great Britain. The sections on "Action and Uses" in this supplement will interest many who are not concerned with pharmaceutical details. They give a summary of some of the more important recent advances in pharmacology and therapeutics, and are more balanced and more authoritative than many of the corresponding sections in the Codex, which have retained much that is now archaic, probably because there was no definite reason for believing it to be incorrect.

\section{Aircraft Instruments}

By George Ellis Irvin. Pp. $x+506$. (New York and London: MeGraw-Hill Book Co., Inc., 1941.) $35 s$.

$T$ HIS book is composed mainly of detailed descriptions, with comprehensive maintenance and testing schedules, of standard American products; the thoroughness which is characteristic of American trade booklets is evident in the treatment. Other than the omission of oxygen instruments and of the absence of synchroscopes from the chapter "Tachometers and Synchronizers", the volume covers most of the American instruments in general use. It is excellently illustrated and reproduced, and in this respect is marred only by a number of proof-reading errors.

The author makes little attempt to explain the physical conceptions leading to the design of flight and navigation instruments, and it is perhaps as well that the scope of the book is restricted in this direction. For example, the statement "Air-speed indicators show the speed of the airplane relative to the air through which it is travelling" is incorrect, unfortunately for the navigator; and in the chapter on compasses, some confusion over the north end of a magnet is evident.

The useful properties of all the instruments are fully described, but their limitations, both fundamental and in practical usage, receive little critical attention. The book is useful for reference purposes, but it cannot be recommended to the serious student of aeronautics or instrument design. 